\title{
NOTES
}

\section{Study of Photopolymers XXXXII. Synthesis and Photochemical Reaction of Water Soluble Self-Sensitized Photoreactive Polymers Using 1,8-Diazabicyclo-[5.4.0]-7-undecene (DBU) Method}

\author{
Tsutomu ShImokawa, ${ }^{*}$ Takahiro Suzuki, and Tadatomi Nishikubo ${ }^{\dagger}$ \\ Department of Applied Chemistry, Faculty of Engineering, \\ Kanagawa University, Rokkakubashi, \\ Kanagawa-ku, Yokohama 221, Japan \\ (R.eceived January 31, 1994)

\begin{abstract}
KEY WORDS 1,8-Diazabicyclo-[5.4.0]-7-undecene (DBU) Method / Poly(acrylic acid) / Propargyl Bromide / 2-Bromomethylanthraquinone / Water Soluble Self-Sensitized Photosensitive Polymer / Relative Photosensitivity /
\end{abstract}

1,8-Diazabicyclo-[5.4.0]-7-undecene (DBU) is a very useful and interesting reagent for modifying anionic polymers. Recently, some anionic polymers such as poly(methacrylic acid $)^{1-3}$ and poly(4-hydroxystyrene $)^{4}$ have been converted to corresponding photosensitive polymers by the reaction with alkyl halides containing photoreactive groups using DBU. These reactions proceeded very smoothly under mild conditions. The reaction of poly(methacrylic acid) and propargyl bromide proceeded especially well at room temperature. DBU can also be used as a suitable reagent for polycondensation between dicarboxylic acids and alkylene dihalides ${ }^{5}$ and for intra-molecular condensation of polyamic acids. ${ }^{6}$

This article reports on the application of this quite unique method for the synthesis of water soluble self-sensitized photosensitive polymers by the reaction of poly(acrylic acid) (PAA) with propargyl bromide (PB) and 2-bromomethylanthraquinone (BMAQ).

\section{EXPERIMENTAL}

\section{Reagents}

PAA was prepared by the radical polymerization of acrylic acid using 4,4'-azobisisobutylonitlile in ethanol, purified by reprecipitation from ethanol into diethyl ether, and dried in vacuo at $50^{\circ} \mathrm{C}$. The yield of PAA was $100 \%$. Reduced viscosity measured at $0.5 \mathrm{~g} \mathrm{dl}^{-1}$ in dimethylformamide (DMF) at $30^{\circ} \mathrm{C}$ was $0.34 \mathrm{dl} \mathrm{g}^{-1}$. BMAQ was synthesized in $50 \%$ yield by the reaction of 2 -methylanthraquinone and $\mathrm{N}$-bromosuccinylimide according to the reported method. ${ }^{7}$

Typical Procedure for the Reaction of PAA with $P B$ to obtain Polymer with Pendant Propargyl Group (P-1)

Partially propargylated PAA (P-1) was prepared as follows: $17.29 \mathrm{~g}(0.24 \mathrm{~mol})$ of PAA was dissolved in $200 \mathrm{ml}$ of DMSO and $17.13 \mathrm{~g}$ $(0.14 \mathrm{~mol} ; 60 \mathrm{~mol} \%$ to PAA) of PB and $40.19 \mathrm{~g}$ $(0.26 \mathrm{~mol})$ of $\mathrm{DBU}$ were added into the PAA/DMSO solution and stirred for $1 \mathrm{~h}$ at

${ }^{\dagger}$ To whom all correspondence should be addressed.

* Present address: Japan Synthetic Rubber Co., Ltd., Tokyo Research Laboratory, 3-5-1 Higasi-Yurigaoka, Aso-ku, Kawasaki 215, Japan. 
$50^{\circ} \mathrm{C} .100 \mathrm{ml}$ of acetic acid was then added to the solution and the reaction mixture was poured into water. The recovered polymer was purified by reprecipitation twice from THF into water and from THF into diethyl ether, and was then dried in vacuo at $50^{\circ} \mathrm{C}$. The yield of P-1 was $10.30 \mathrm{~g}$. Degree of esterification of the obtained polymer was $59.8 \mathrm{~mol} \%$ (calculated from ${ }^{1} \mathrm{H}$ NMR peaks and titration by $0.1 \mathrm{~N}$ $\mathrm{KOH} /$ methanol solution). Reduced viscosity of this polymer measured at $0.5 \mathrm{~g} \mathrm{dl}^{-1}$ in DMF at $30^{\circ} \mathrm{C}$ was $0.48 \mathrm{dlg}^{-1}$. The IR spectrum (film) showed absorption peaks at $3280 \mathrm{~cm}^{-1}$ ( $\equiv \mathrm{C}-\mathrm{H}), 2150 \mathrm{~cm}^{-1}(\mathrm{C} \equiv \mathrm{C}), 1740 \mathrm{~cm}^{-1}(\mathrm{C}=$ O). The ${ }^{1} \mathrm{H}$ NMR (DMSO- $d_{6}$, internal standard TMS) spectrum showed proton signals at $\delta=1.4-2.2$ (main chain $-\mathrm{CH}_{2}-$ ), 2.2-2.4 (main chain - $\mathrm{CH}-$ ), 3.4-3.6 $(\mathrm{C}-\mathrm{H})$, and 4.4-4.8 ppm (O- $\left.\mathrm{CH}_{2}-\mathrm{C}\right)$, respectively.

Typical Procedure for the Reaction of P-1 with $B M A Q$

A typical procedure for synthesis of selfsensitized photosensitive polymer using P-1 and BMAQ is as follows; $1.00 \mathrm{~g}$ of $\mathrm{P}-1$ (containing $4.2 \mathrm{mmol}$ of carboxyl group) and $0.65 \mathrm{~g}(4.2 \mathrm{mmol})$ of DBU was dissolved in $5 \mathrm{ml}$ of DMF. To the solution, $0.11 \mathrm{~g}(0.35 \mathrm{mmol}$; $3.3 \mathrm{~mol} \%$ for P-1) of BMAQ dissolved in $5 \mathrm{ml}$ of DMF and $5 \mathrm{ml}$ of methanol were added under stirring. After $24 \mathrm{~h}$ at $50^{\circ} \mathrm{C}, 5 \mathrm{ml}$ of acetic acid was added and the reaction mixture was poured into water. The polymer was purified by reprecipitation twice from THF into water and from THF into diethyl ether, and was then dried in vacuo at $50^{\circ} \mathrm{C}$. The yield of the polymer
(P-2) was $0.76 \mathrm{~g}$. Degree of esterification of the polymer was $3.2 \mathrm{~mol} \%$ (calculated from ${ }^{1} \mathrm{H}$ NMR). Therefore, this polymer contained $59.8 \mathrm{~mol} \%$ of propargyl group, $3.2 \mathrm{~mol} \%$ of anthraquinolyl-methyl (AQM) group, and $37.0 \mathrm{~mol} \%$ of carboxyl group, respectively. Reduced viscosity of this polymer measured at $0.5 \mathrm{~g} \mathrm{dl}^{-1}$ in DMF at $30^{\circ} \mathrm{C}$ was $0.49 \mathrm{dl} \mathrm{g}^{-1}$. The IR spectrum (film) showed absorption peaks at $1680 \mathrm{~cm}^{-1}(\mathrm{Ar}-\mathrm{CO}-\mathrm{Ar}), 1600 \mathrm{~cm}^{-1}$ (Aromatic ring). The ${ }^{1} \mathrm{H}-\mathrm{NMR}$ (DMSO- $d_{6}$, internal standard TMS) spectrum showed proton signals at $\delta=5.1-5.3\left(\mathrm{O}-\mathrm{CH}_{2}-\mathrm{Ar}\right)$ and 7.5-8.2 ppm (Aromatic proton), respectively.

\section{Synthesis of Water Soluble Self-Sensitized Photosensitive Polymer}

Water soluble self-sensitized photosensitive polymer was prepared as follows; $0.2 \mathrm{~g}$ of $\mathrm{P}-2$ (containing $0.74 \mathrm{mmol}$ of carboxyl group) was dissolved in $10 \mathrm{ml}$ of tetrahydrofuran (THF), and $7.40 \mathrm{ml}$ of $0.1 \mathrm{~N} \mathrm{KOH}$ methanol solution was added. The solution was poured into diethyl ether and the precipitated polymer was dried in vacuo. The yield of the polymer was $0.19 \mathrm{~g}$. Reduced viscosity of this polymer was $2.19 \mathrm{dlg}^{-1}$, measured at $0.5 \mathrm{~g} \mathrm{dl}^{-1}$ in water at $30^{\circ} \mathrm{C}$.

The synthetic process of the water soluble self-sensitized photosensitive polymer is shown in Scheme 1 and results are summarized in Tables I and II.

\section{Photochemical Reaction of the Polymer}

Rates of photochemical reaction and relative photo-sensitivity of the obtained polymers were

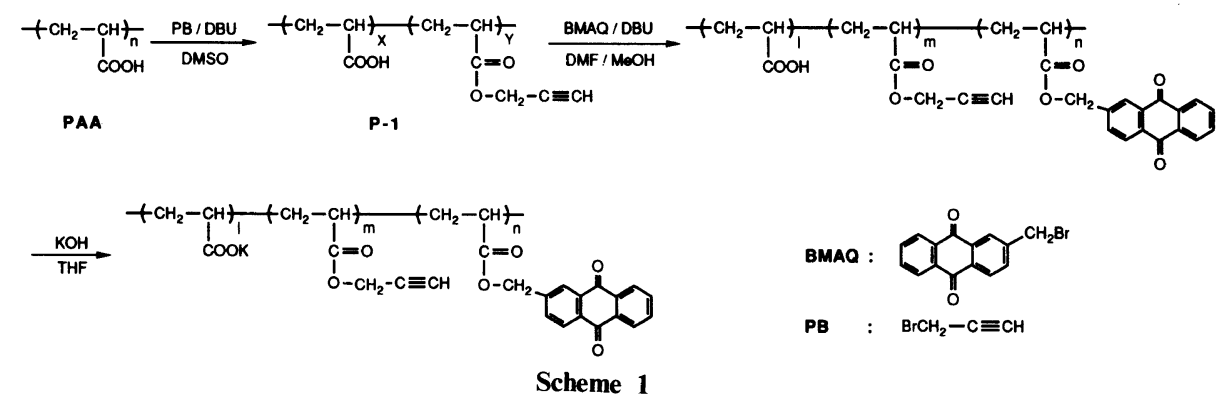


Water Soluble Self-Sensitized Photosensitive Polymer

Table I. Synthesis of self-sensitized photosensitive polymers ${ }^{\mathbf{a}}$

\begin{tabular}{|c|c|c|c|c|c|c|c|c|}
\hline \multirow{2}{*}{$\begin{array}{c}\text { Polymer } \\
\text { No. }\end{array}$} & \multicolumn{2}{|c|}{ BMAQ } & \multirow{2}{*}{$\frac{\mathrm{DMF} / \mathrm{MeOH}}{\mathrm{ml}}$} & \multirow{2}{*}{$\frac{\text { Yield }}{\mathrm{g}}$} & \multicolumn{3}{|c|}{ Composition of polymer $(\mathrm{mol} \%)^{b}$} & \multirow{2}{*}{$\frac{\eta_{\mathrm{sp}} / c^{c}}{\mathrm{dlg}^{-1}}$} \\
\hline & $\mathrm{mmol}$ & $\mathrm{mol} \%$ & & & AA & PA & AQM & \\
\hline P-2 & 0.35 & 3.3 & $10 / 5$ & 0.76 & 37.0 & 59.8 & 3.2 & 0.49 \\
\hline P-3 & 0.70 & 6.6 & $10 / 5$ & 0.83 & 34.5 & 59.8 & 5.7 & 0.46 \\
\hline$P-4$ & 1.05 & 9.9 & $15 / 5$ & 0.79 & 33.7 & 59.8 & 6.5 & 0.47 \\
\hline P-5 & 1.40 & 13.2 & $15 / 5$ & 0.95 & 31.6 & 59.8 & 8.6 & 0.45 \\
\hline
\end{tabular}

a Reaction was carried out using $1.00 \mathrm{~g}$ of P-1 (10.5 mmol, containing $4.2 \mathrm{mmol}$ of carboxyl group) and $4.2 \mathrm{mmol}$ of DBU at $50^{\circ} \mathrm{C}$ for $24 \mathrm{~h}$.

b AA as acrylic acid unit, PA as propargyl acrylate unit, AQM as 2-anthraquinolyl methyl acrylate unit, respectively.

c Measured at concentration of $0.5 \mathrm{~g} \mathrm{dl}^{-1}$ in $\mathrm{DMF}$ at $30^{\circ} \mathrm{C}$.

Table II. Synthesis of water soluble self-sensitized photosensitive polymers ${ }^{\mathrm{a}}$

\begin{tabular}{|c|c|c|c|c|}
\hline \multirow{2}{*}{$\begin{array}{c}\text { Polymer } \\
\text { No. }\end{array}$} & \multirow{2}{*}{$\begin{array}{c}\text { Used } \\
\text { polymer }\end{array}$} & \multirow{2}{*}{$\frac{0.1 \mathrm{~N} \mathrm{KOH}}{\mathrm{ml}}$} & \multirow{2}{*}{$\frac{\text { Yield }}{\mathrm{g}}$} & \multirow{2}{*}{$\frac{\eta_{\text {sp/c }}{ }^{b}}{\mathrm{dl} \mathrm{g}^{-1}}$} \\
\hline & & & & \\
\hline P-6 & P-2 & 7.40 & 0.19 & 2.19 \\
\hline P-7 & P-3 & 6.40 & 0.15 & 2.80 \\
\hline P-8 & P-4 & 6.10 & 0.14 & 2.63 \\
\hline P-9 & P-5 & 6.10 & 0.13 & 1.89 \\
\hline
\end{tabular}

a Reaction was carried out using $0.20 \mathrm{~g}$ of selfsensitized photosensitive polymer in $10 \mathrm{ml}$ of THF at room temperature.

b Measured at concentration of $0.5 \mathrm{~g} \mathrm{dl}^{-1}$ in water at $30^{\circ} \mathrm{C}$.

determined as reported $^{1}$ previously by IR spectroscopy and the gray scale method in the film state, respectively. P-1 and P-5 films were cast from THF solution, and P-9 film was cast from aqueous solution.

\section{RESULTS AND DISCUSSION}

Recently we reported ${ }^{2}$ the reaction of poly(methacrylic acid) (PMA) with BMAQ using DBU in dimethyl sulfoxide (DMSO). During the esterification reaction, a side reaction was observed. It was also found that the side reaction induced a decrease in the degree of esterfication and produced a polymer of dark brown color. In the case of the reaction between P-1 and BMAQ, the same phenomenon was observed. Ono et al. reported ${ }^{8}$ the reaction of low molecular weight carboxylic acid with alkyl halide using DBU. In that paper they pointed out that the complex of the carboxylic acid with DBU is a strong nucleophile but is only weakly basic.

Therefore, it seems that the observed side reaction did not derive from the reaction of P-1/DBU complex with BMAQ. Thus, it was considered that there is an equilibrium between free DBU and P-1/DBU complex, and that a small amount of free DBU acts as a strong base to induce the side reaction as in the $\alpha$-elimination reaction of BMAQ. If the equilibrium should lean toward complex formation due to addition of polar protic solvent, the ratio of the side reaction would be decreased. Accordingly, methanol was used as a stabilizer for the complex state of the DBU. The esterification reaction of $\mathrm{P}-1$ with $\mathrm{BMAQ}$ proceeded very smoothly in high conversion without any side reaction in the mixed solvent such as DMF/methanol, and produced a polymer colored a faint yellow.

Water soluble self-sensitized polymers were prepared by the neutralization of P-2 - 5 containing pendant carboxylic acid groups with $\mathrm{KOH} /$ methanol solution in THF.

When the polymer films were irradiated with a $250-W$ high-pressure mercury lamp, the cross-linking reaction of pendant propargyl group was induced very effectively by the 


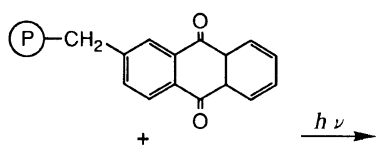<smiles>O=C1c2ccc(Cc3ccccc3)cc2C(O)C2CCCCC12</smiles>

\section{(P) $-\mathrm{CH}_{2}-\mathrm{C} \equiv \mathrm{CH}$}

Crosslinking Reaction

(P) $-\mathrm{CH}_{2}-\mathrm{C} \equiv \mathrm{CH}$

(P) $-\mathrm{CH}_{2}-\mathrm{C}=\mathrm{C}$.

Scheme 2

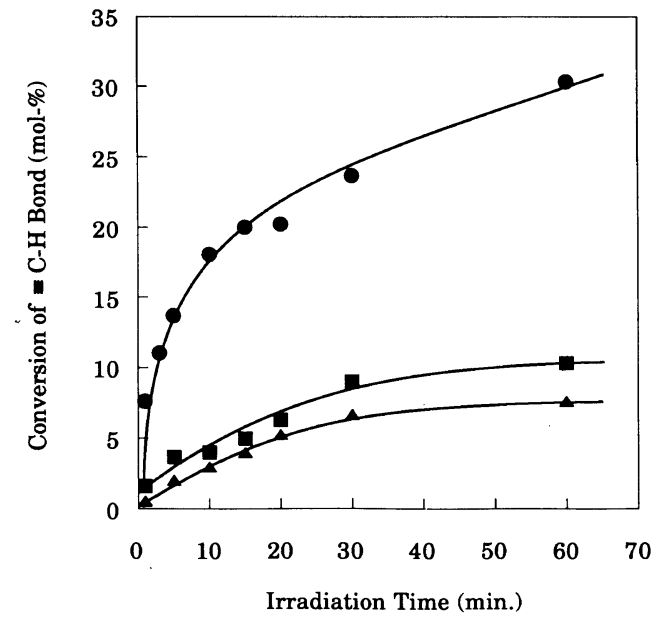

Figure 1. Rate of photochemical reaction of polymers.

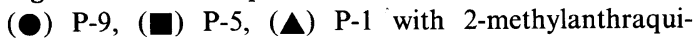
none ( $5 \mathrm{~mol} \%$ for propargyl group).

pendant AQM groups as shown in Scheme 2. The absorption peak at $3280 \mathrm{~cm}^{-1}$ due to the $\equiv \mathrm{C}-\mathrm{H}$ bond in the polymers clearly decreased, and the results are summarized in Figure 1. As can be seen, the order of the reaction rate was P-9, P-5, and P-1 with 2-methylanthraquinone. It seems that the higher reaction rate of P-9 compared with P-5 was due to the coagulation effect. That is, micro-phase-separation may have occurred between both the pendant potassium carboxylate groups and the two ester groups such as the photosensitizer and photoreactive moieties in the polymer film as shown in Figure 2.

The relative photosensitivity, which was measured by the gray scale method, also showed the same relative order as the above rate of the photochemical reaction, and the photosensitivity of self-sensitized photosensi-

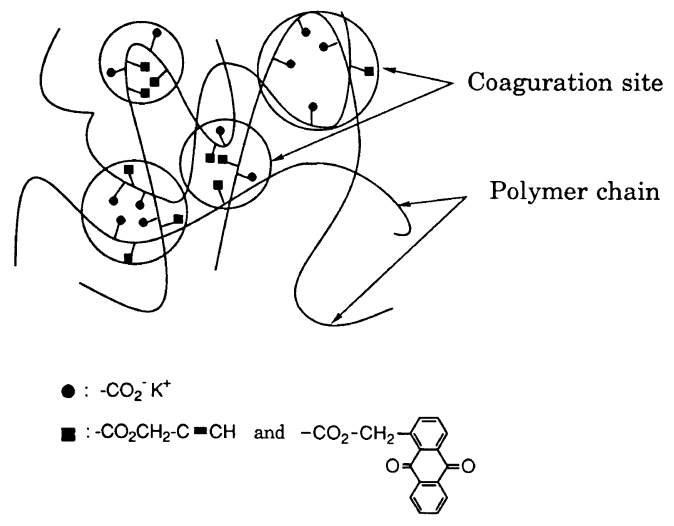

Figure 2. Coagulation model of functional groups in water soluble self-sensitized photosensitive polymer film. (O) carboxylate groups; ( $\mathbf{\square})$ ester groups.

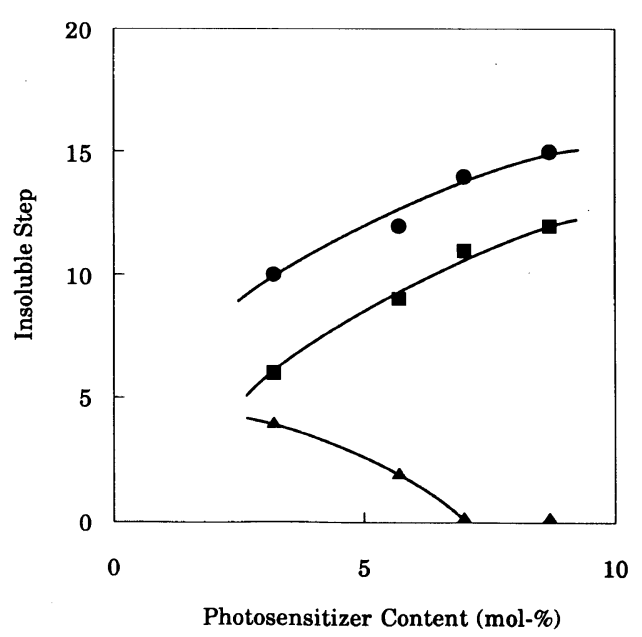

Figure 3. Relationship between content of photosensitizing group and relative photosensitivity. (O) water soluble self-sensitized photosensitive polymers (developed by water); ( $\square$ ) self-sensitized photosensitive polymers [developed by methyl ether ketone $(15 \mathrm{v}) /$ ethyl acetate (85v)]; (A) P-1 with 2-methylanthraquinone [developed by acetone $(50 \mathrm{v}) /$ methanol $(50 \mathrm{v})]$. 
tive polymers (P-2-5) and water soluble self-sensitized photosensitive polymers (P-69) increased with increasing content of AQM groups in the polymers (Figure 3).

On the other hand, P-1 with 2-methylanthraquinone system showed decrease in the photosensitivity with increasing 2-methylanthraquinone content. This is because 2-methylanthraquinone separated from the film during the coating process due to their immisciblility which shaded the incident light coming into the polymer film.

From the above results, it is clear that watersoluble self-sensitized photosensitive polymers can be synthesized very easily by the DBU method, and the thus-obtained polymers will have high photosensitivity and excellent coating properties.

\section{REFERENCES}

1. T. Shimokawa and T. Nishikubo, Kobunshi Ronbunshu, 44, 641 (1987).

2. T. Shimokawa, H. Hatori, and T. Nishikubo, Kobunshi Ronbunshu, 49, 577 (1992).

3. K. Inomata, T. Nishikubo, and T. Shimokawa, $J$. Photopolym. Sci. Technol., 2, 21 (1989).

4. T. Nishikubo, T. Iizawa, A. Takahashi, and T. Shimokawa, J. Polym. Sci., A, Polym. Chem., 28, 105 (1990).

5. T. Nishikubo and K. Ozaki, Polym. J., 22, 1403 (1990).

6. T. lizawa and E. Seno, Polym. J., 24, 1169 (1992).

7. M. D. Bhavsr, B. D. Tilak, and K. Venkataraman, J. Industr., 163, 392 (1957).

8. N. Ono, T. Yamada, T. Saito, K. Tanaka, and A. Kaji, Bull. Chem. Soc. Jpn., 51, 2401 (1978). 